Historic, Archive Document

Do not assume content reflects current scientific knowledge, policies, or practices. 



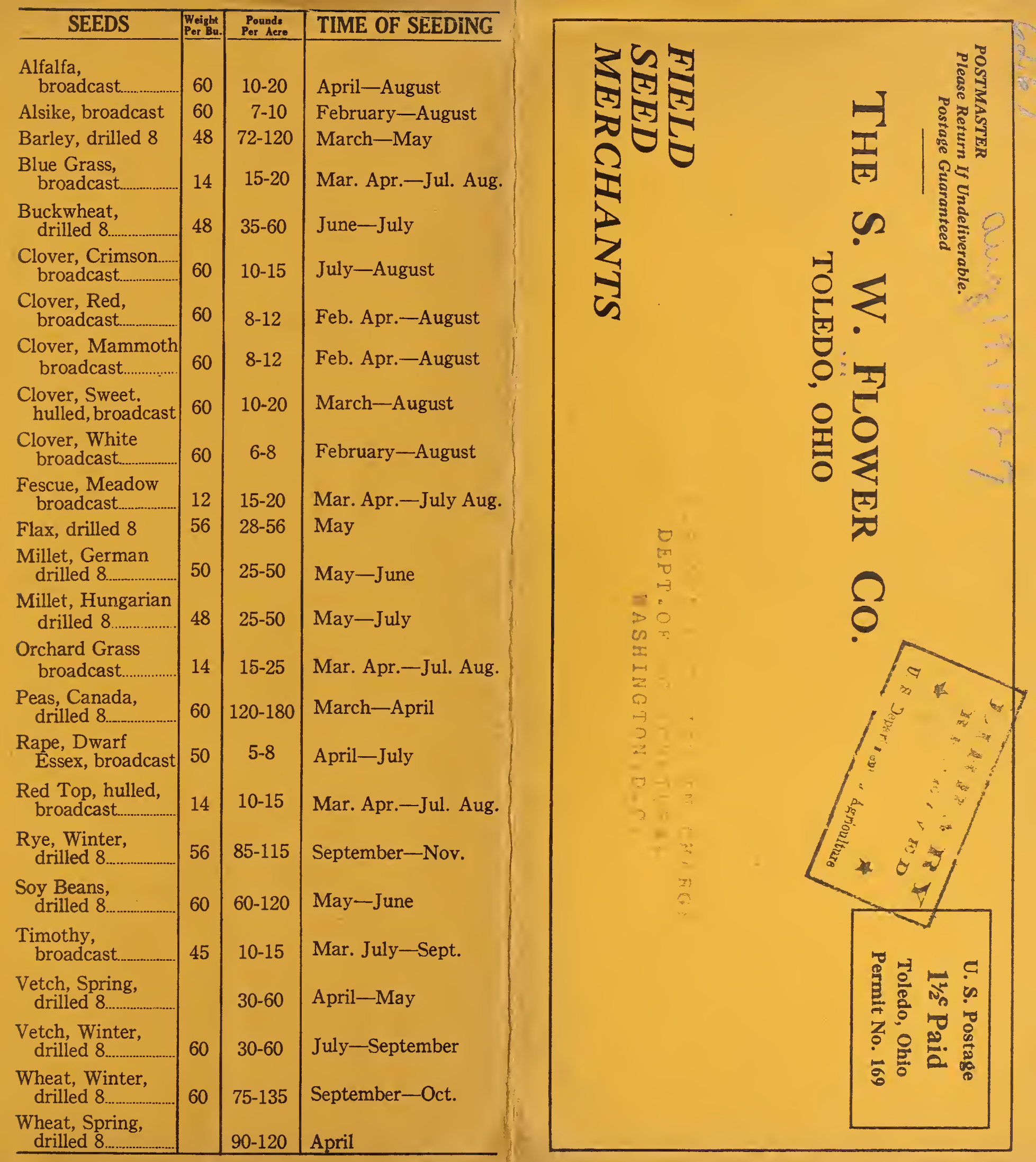





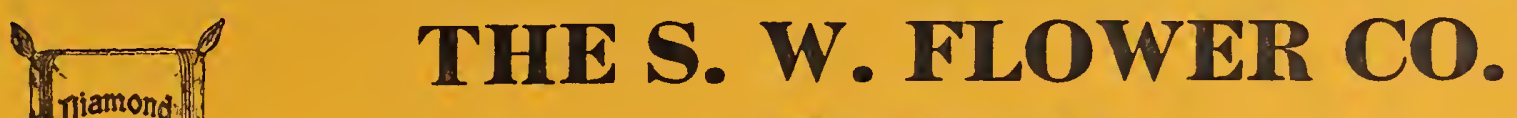

802 Lafayette St.

Next Issue, Weekly

TOLEDO, OHIO

August 19, 1927

REDCLOVER

ALSIKE

ALFALFA

TIMOTHY

LAWN

GRASS

TERMS:-Cash.

No Discount

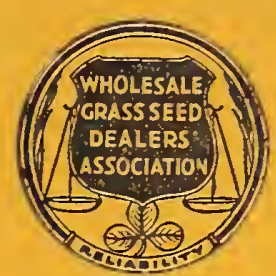

Telephone

MAin 6191

Telephone calls and telegrams cost meneg. cur asking more money for our doods.

Quotations for prompt shipment subject market changes and unsol. . Prices f.o.b. Toledo.

Bags extra at value unless otherwise specified, not retrumable Printers and manifest errors excepted.

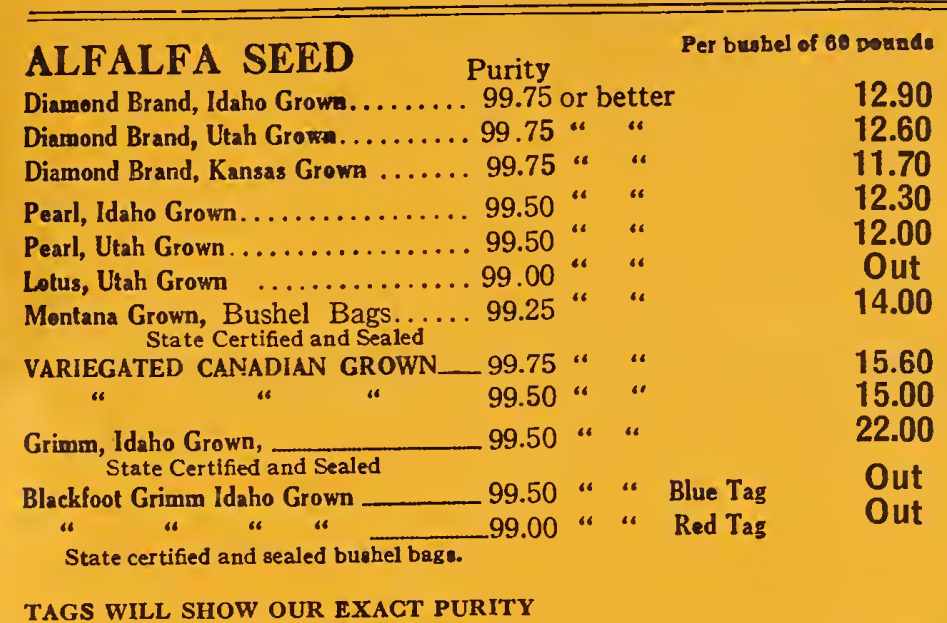

TAGS WILL SHOW OUR EXACT PURITY

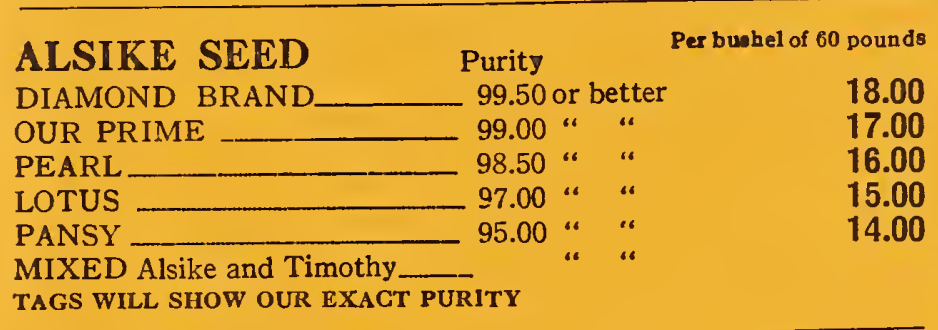

\section{GLOVER SEED}

Medium - Domestic Grown

DIAMOND BRAND -...-. 99.50 or better

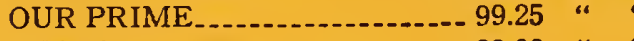

PEARL -

SPECIAL-OHIO GROWN_... 85.00 “" “ “ Appli-

IDAHO “"

Mammoth - Domestic Grown

OUR PRIME .................99.50 " "

PEARL........................ " "

LOTUS

Medium-Imported-French

About $1 \%$ stained green according to

Federal Law

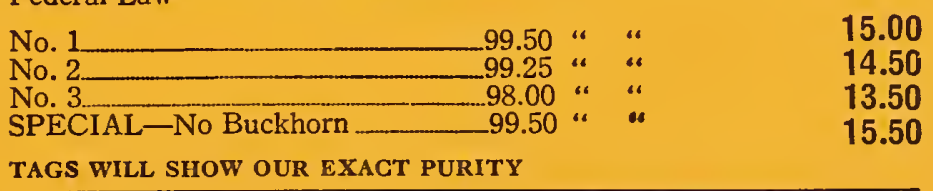

\section{SWEET CLOVER ALL SCARIFIED}

$$
\text { Diam }
$$


If you have seed to sell send samples with lowest prices

Before buying take our qualities into consideration

Samples on request

"The Best is the Cheapest"

We sell for future shipment

If interested ask for quotations

Better Seeds 